\title{
FACTORS MOTIVATING PRESERVICE TEACHERS FOR ONLINE LEARNING WITHIN THE CONTEXT OF ARCS MOTIVATION MODEL
}

\author{
Serkan IZMIRLI \\ Canakkale Onsekiz Mart University, Canakkale, TURKEY \\ Ozden SAHIN IZMIRLI \\ Canakkale Onsekiz Mart University, Canakkale, TURKEY
}

\section{ABSTRACT}

The purpose of this study was to determine the factors motivating pre-service teachers for online learning within the context of ARCS motivation model. The study, in which the phenomenology model was used, was carried out with 52 pre-service teachers attending the department of Computer Education and Instructional Technologies at the Education Faculty of Çanakkale Onsekiz Mart University in Turkey.

The participants were experienced in online learning. In the study, the data were collected with an open-ended questionnaire within the framework of the ARCS motivation model. The research data were analyzed with descriptive analysis and examined fewer than four themes (attention, relevance, confidence and satisfaction).

Also, for each theme, sub-themes were obtained. The most frequent factor motivating for online learning was "relevance to individual differences" found under the theme of "confidence". As for the least frequent motivating one, it was "flexibility" found under the theme of "relevance".

Keywords: Online learning, motivation in online learning, ARCS model.

\section{INTRODUCTION}

Today, it is a well-known fact that with the development of technology, web-based tools (social networks, wikis, blogs and so on) are integrated into education and are thus commonly used in online learning (Mcgreal \& Elliott, 2008). Online learning is referred to as environments (like the Internet or the Intranet) using network technology to deliver, support and assess the formal or informal instructional content (Shank \& Sitze, 2004). When the use of online learning environments is taken into consideration, a course can be taught in three ways:

Entirely online: The course is taught completely online. For instance, the lessons can be taught entirely online via Moodle, which is a learning management system.

A blend of online and face-to-face: The course is taught with the blend of online and faceto-face methods of instruction. The lessons can be taught partly on online basis and partly on face-to-face basis. For example, for the first seven weeks, the course can be taught using the face-to-face method, and for the following seven weeks, Moodle can be used for online teaching. 
Online support to face-to-face: Face-to-face teaching can be supported with an online environment. For instance, such web-based tools as blogs, Twitter, Edmodo and Facebook can be used to support face-to-face teaching. Lessons are taught completely on face-toface basis, and the web-based tools are used for such purposes as collecting the homework, holding discussions and sharing materials.

Online learning has brought about several issues besides certain renovations in education. One of the main issues regarding online learning is the learner motivation (Bonk, 2002). Learner motivation is the extent to which the learner makes effort in and pays attention to various activities. Learners are likely to get motivated to learn via an activity even if they do not find the content interesting. Motivation to learn is to adopt learning goals and related strategies (Brophy, 2010).

Motivation is likely to have influence on students' performance (Gabriele, 2003). Motivation to learn is an important factor for students to become successful in online learning (Keller, 1999). When motivation to learn is low, the potential to learn may decrease (Hodges, 2004; Wlodkowski, 1985; Yukselturk \& Bulut, 2007). In online learning environments, doing designs by determining students' motivational requirements can increase their motivation and performance (Keller \& Suzuki, 2004). Here, use of motivation models could be said to be useful. One of the commonly used motivation models is Keller's ARCS motivation model (1987a).

\section{ARCS MOTIVATION MODEL AND MOTIVATION IN ONLINE LEARNING}

John Keller states that it is necessary to consider the dimensions of attention, relevance, confidence and satisfaction (ARCS) in the phase of designing learning environments while maintaining motivation in learning processes. In ARCS model, the dimension of attention allows drawing and maintaining the attention with the help of different instructional design strategies or applications. Attention-drawing strategies include not only providing interesting graphics or animations that put learners into contradiction regarding their past experiences but also diversifying the medium of instruction (films, videos and so on). In the dimension of relevance, the reason why students should study for their lessons should be clarified. Determining learners' interests and associating their interests with instruction are among relevance strategies. In the dimension of confidence, students should be encouraged to attend courses regularly and to become successful in courses. Clear statement of learning goals and the organization of learning materials from simple to complex are among confidence strategies. As for the dimension of satisfaction, students feel themselves better when they achieve a task. Giving awards and reinforcers is among satisfaction strategies (Keller, 1987a; Keller \& Suzuki, 2004).

It could be stated that the ARCS model was developed to examine motivation primarily in face-to-face learning environments. Parallel to the changing technologies and learning environments, motivation has become an issue of concern in online learning environments. Keller (1997) reported that online environments could themselves manage to draw the attention of learners due to the novelty of online environments although instructional designers design learning environments without considering the factors motivating online learners in the period of newly-spread online environments. However, it is pointed out that this interest decreases in time as students become familiar with the environment (Clark, 2001; Keller \& Suzuki, 2004). Also, the drop-out rate for online courses is fairly high (Bonk, 2002; Levy, 2007).

It is reported that student satisfaction is the basic indicator of attending online courses (Levy, 2007). Students' discontent with online learning decreases their motivation and thus do not attend the courses (Chyung, 2001; Sun, Tsai, Finger, Chen \& Yeh, 2008). 
Therefore, during online courses, students' motivation should be maintained at high levels with the help of instructional activities (Yukselturk \& Bulut, 2007). However, an important question here is "How should learning activities be designed to increase learner motivation?" Determining the factors that motivate learners for online learning could contribute to the selection of instructional activities.

When the related literature is examined, it is seen that there is limited research on how to increase learner motivation in technology-aided instructional environments (Gabrielle 2003). In addition, it is stated that motivation principles are rarely taken into consideration in the design of online learning environments (Bonk, 2002). For this reason, it is pointed out that it is important to investigate online learner motivation (Bonk, 2002; Chen \& Jang, 2010) and that there is a need for further research evaluating learner motivation in online learning environments (Smith, 2008). Determining the factors that motivate learners in the process of online learning could be said to provide instructional designers with important implications.

When the factors that motivate learners in technology-aided instructional environments are identified, learners' motivation and performances could be increased with appropriate strategies (Gabrielle, 2003). In order to maintain learner motivation in the design of technology-aided instructional environments, the ARCS model can be used (Song \& Keller, 2001). Similarly, it is pointed out that the ARCS model can be considered for the design of online learning environments (Chyung, 2001; Keller \& Suzuki, 2004; Miltiadou \& Savenye, 2003; Smith, 2008). However, the dimensions found in the ARCS motivation model do not explain which motivational tactics, or when, will be used for students. For this reason, it is necessary to develop the motivational tactics that meet students' characteristics and needs (Keller, 1987b). Determining the motivating factors for online learners could be said to contribute positively to the design of an environment as well as to the learner's performance.

In literature, there are a number of studies conducted to investigate the motivating factors for online learning. Sun, Tsai, Finger, Chen and Yeh (2008) examined the important factors influential on learners' satisfaction in e-learning. In their study carried out with e-learners, they determined the important factors influential on learners' satisfaction in e-learning as computer anxiety, the trainer's attitudes towards e-learning, course flexibility, course quality, perceived usefulness, perceived ease of use and diversity in assessments. Sawang, Newton \& Jamieson (2013), in their study conducted with employees taking online training in an institution, found out that satisfaction with elearning had a significant relationship with authentic activities provided, with the institution's support to e-learning and with learners' openness to changes. In another study carried out by Mclaren (2010), the researcher aimed at determining the influence of instructor-learner interaction on learner's satisfaction in online M.A. courses. The results of the study revealed that instructor feedback, instructional immediacy, instructor availability and transactional distance all had influence on online learners' satisfaction. Law, Lee and $\mathrm{Yu}$ (2010) determined the motivational factors for university students taking the course of computer programming with e-learning support. The results of their study revealed that "individual attitudes and expectations", "clear instructions" and "reward and recognition" were important motivators.

Apart from these studies determining the learners' views about the factors that motivate for online learning, there are other studies carried out to determine the views of the teaching staff giving online education. Bonk (2002) examined the motivational characteristics of web-based learning taking the views of those giving online education (corporate trainers, instructional designers, training managers and so on). In the study, relevant and meaningful materials, timely and responsive feedback, goal-driven and 
product-oriented activities and personal growth were found highly important for webbased learning.

When research on motivation in online learning was examined, it was seen that various factors were influential on motivation and on satisfaction, which is a sub-dimension of motivation according to the ARCS model. In addition, it is obvious that these studies were generally carried out in a certain setting and designed with the quantitative approach. It could be stated that qualitative studies should be designed to collect in-depth data in different settings. In this respect, the purpose of the present study was to determine the motivating factors in online learning for preservice teachers within the scope of the ARCS motivation model.

\section{METHOD}

\section{Research Model}

The study was designed as phenomology to help understand the motivating factors for students in online learning environments within the framework of the participants' experiences. Phenomology can be regarded as a way of personal perception of a phenomenon or experience. In other words, events are presented from the perspective of the participants (Mertens, 2009). In phenomenology studies, the basic question is "What are the experiences regarding the situation from the perspectives of the participants determined?" (Patton, 2002).

\section{Study Group}

The study was conducted in an Education Faculty of a state university in Turkey with the participation of a total of 59 students ( 24 female, and 35 male) from the Department of Computer Education and Instructional Technologies (CEIT). Of all the participants, seven of them were junior students, and 52 of them were senior students. The participants were determined with the purposeful sampling method. In this respect, for the purpose of explaining the research phenomenon more clearly, the process followed to determine the participants regarding the related subject, which could be called "information rich" (Patton, 1990), was as follows:

$>$ The research subject required the participation of students who had theoretical and practical knowledge about online learning. For this reason, the study was carried out with CEIT students taking theoretical and practical courses regarding online learning at Education Faculty. It is a fact that CEIT students have experience in online learning within the scope of several courses.

$>$ When the curriculum of CEIT department is examined, it is seen that courses related to online learning are often taught to junior and senior students.

Therefore, as junior and senior students are more likely to be knowledgeable about online learning, the study was carried out only with junior and senior students.

\section{Data Collection Tool}

The data collection tool used in the study was an online questionnaire form made up of four open-ended questions and developed by the researchers within the framework of the ARCS model. The measurement tool included one question for each of the dimensions of the ARCS model. The open-ended questionnaire form developed was examined by a CEIT faculty member for its face validity and content validity. In addition, the questionnaire 
form was piloted with a junior student attending the department of CEIT. The views determined helped decide to inform the research participants about the dimensions of the ARCS model. In this respect, before the application of the questionnaire, the dimensions of the ARCS model were explained to the participants, and they were asked to respond to the questions according to each dimension. The questions included in the questionnaire form were as follows:

What are the motivating factors in online learning for you? Please provide answers within the framework of the dimensions below:

$>$ Explain the factors in detail that draw your attention.

$>$ Explain the factors in detail that meet your learning needs.

$>$ Explain the factors in detail that make you feel relaxed and confident.

$>$ Explain the factors in detail that make you satisfied.

The first question found in the questionnaire aimed at determining the participants' views about the dimension of "attention" of the ARCS model; the second question about the dimension of "relevance"; the third question about the dimension of "confidence"; and the fourth question about the dimension of "satisfaction".

\section{Data Collection and Analysis}

The research data were collected with an online open-ended questionnaire form. Of all the 155 junior and senior students, 66 of them volunteered to participate in the study. Following the collection of the research data, the responses of 59 students were analyzed with the descriptive analysis method within the framework of the ARCS model found in related literature. In the descriptive analysis phase, the data were examined according to the themes determined based on the related literature (attention, relevance, confidence and satisfaction.

\section{Validity and Reliability}

In qualitative studies, validity means that the researcher objectively observes a phenomenon as it is (Yıldırım and Şimşek, 2008). Thus, in order to collect objective data with the data collection tool, an impartial expert was asked to examine the data collection tool developed based on a model. In addition, for the validity of the data collection tool, it was piloted before the application. Following the data collection process, descriptive analysis was conducted within the theoretical framework (ARCS model) found in related literature. For the sub-themes, the reliability coefficients were calculated. While determining the sub-themes regarding the themes, both researchers examined the data independently of one another.

Depending on the formula suggested by Miles and Huberman (1994), the reliability of the study was calculated as $86 \%$ for the sub-themes of the first theme; $92 \%$ for those of the second theme; $82 \%$ for those of the third theme; and $89 \%$ for the sub-themes of the fourth theme.

In addition, code numbers were assigned to the participants in the study, and the research findings obtained were supported with direct quotations.

\section{FINDINGS}

As can be seen in Figure 1, the factors motivating the preservice teachers of information technologies were grouped under four themes within the context of the ARCS motivation model in line with the research purpose. 


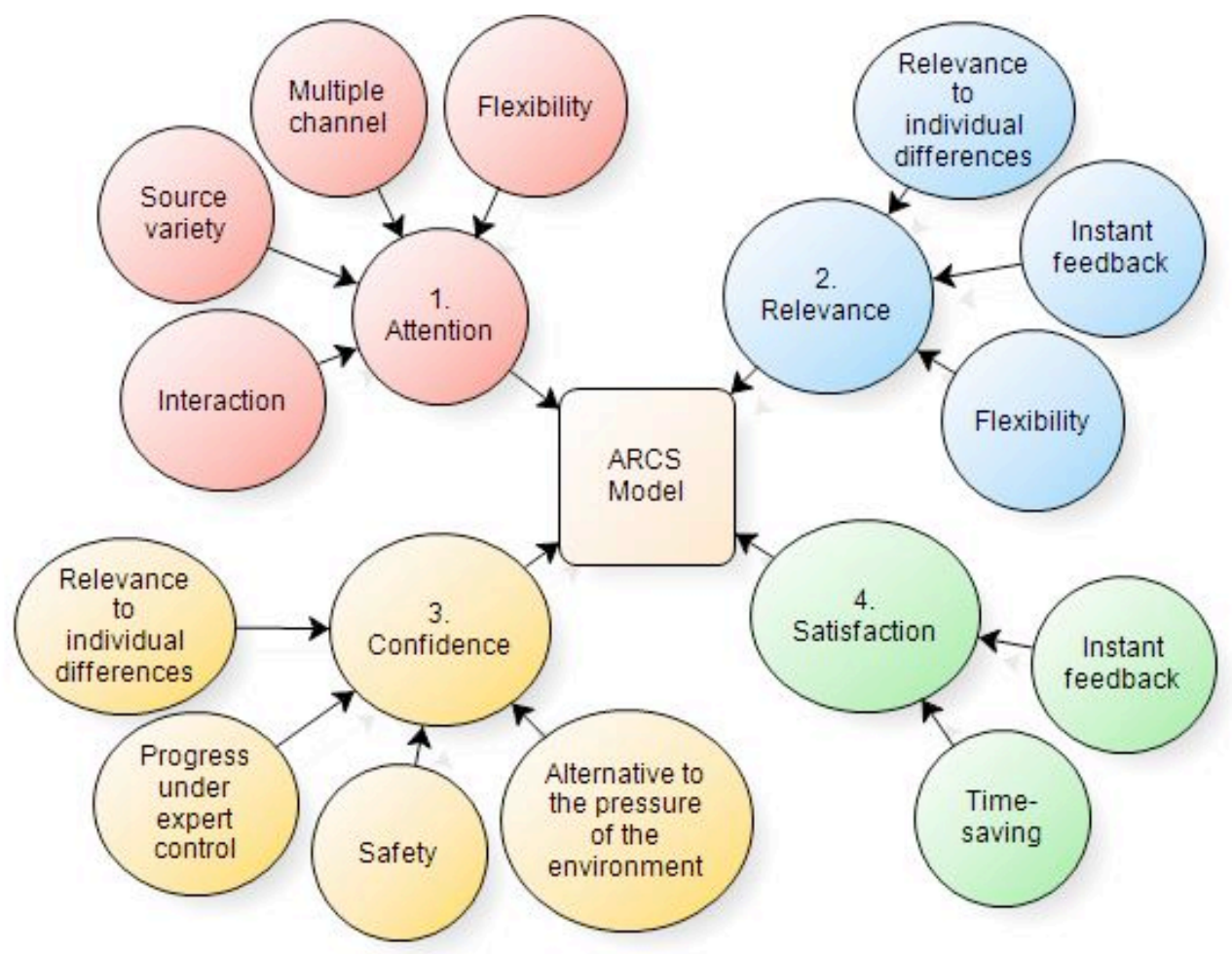

Figure: 1

Themes and Sub-Themes within the Context of the ARCS Model

As can be seen in Figure: 1, the data were examined under four main themes. For each theme, related sub-themes were determined. Table 1 presents the frequencies regarding the themes.

Table: 1

Frequencies regarding the sub-themes and the themes

\begin{tabular}{|c|c|c|}
\hline & Theme heading & f \\
\hline \multirow[t]{5}{*}{ Attention } & & 40 \\
\hline & Flexibility & 19 \\
\hline & Multiple Channel & 9 \\
\hline & Source Variety & 6 \\
\hline & Interaction & 6 \\
\hline \multirow[t]{4}{*}{ Relevance } & & 16 \\
\hline & Relevance to individual differences & 9 \\
\hline & Instant feedback & 4 \\
\hline & Flexibility & 3 \\
\hline \multirow[t]{5}{*}{ Confidence } & & 55 \\
\hline & Relevance to individual differences & 31 \\
\hline & Progress under expert control & 12 \\
\hline & Safety & 6 \\
\hline & Alternative to the pressure of the environment & 6 \\
\hline \multirow{3}{*}{ Satisfaction } & & 12 \\
\hline & Instant feedback & 8 \\
\hline & Time-Saving & 4 \\
\hline
\end{tabular}


Theme of Attention

The theme of attention was made up of four sub-themes. One of the pre-service teachers who pointed out that online learning drew their attention as it provided "flexibility" said

"flexible learning occurs as there is no limitation of time or place, and this makes learning more attractive" (teacher candidate-number 4).

In addition, some of the pre-service teachers stated that the presentation of the instructional content in a way to address "multiple channels" in the online environment drew their attention. Regarding this, one of the students said

"as an attention-drawing factor, the multimedia-learning environment addresses both the ear and the eye" (pre-service teacher-number 24).

Another pre-service teacher who stated that online learning provided "source variety" said;

"you can reach the necessary information more rapidly via a number of sources, and students can also reach the assistant instructor very easily in the online environment" (pre-service teacher-number 17).

Lastly, another pre-service teacher who stated that the "interactive" structure of online learning was attention-drawing said;

"communicating with friends, doing something with them, interacting with the teacher and doing all these things are quite attention-drawing" (pre-service teacher-number 57).

Theme of Relevance

One of the pre-service teachers who stated that online learning allowed "relevance to individual differences" said "I can study a course-related subject whenever I want. It is me who will define the time. To me, this is quite suitable for me. Also, some other students can study on their own styles..." (pre-service teacher-number 5).

Another pre-service teacher who reported that their motivation increased as online learning allowed "instant feedback" said "Since it allows opportunities for instant feedback, it helps determine learning deficiencies and communicate with a classmate easily" (pre-service teacher-number 25). Lastly, one other pre-service teacher who believed online learning provided "flexibility" and helped them get motivated said "Online course materials allow me to learn the subjects later that I haven't understood during the class hour ... this flexibility motivates me ..." (pre-service teacher-number 25).

\section{Theme of Confidence}

This theme was made up of four sub-themes. One of the students who got motivated as online learning allowed "relevance to individual differences" said "...I study in my own environment, and nobody has to see each other... I determine my study environment on my own. It is relaxing for me to be home.... Other people can also direct the process as they want" (preservice teacher-number 32).

Another teacher who stated that $s /$ he got motivated since online learning allowed "progress under expert control" said "I can communicate with the teacher not only during the course hour but also at any other time I want". In addition, establishing communication in the process makes me feel that the process is under control; thus I feel confident" (preservice teacher-number 21). One other preservice teacher who stated that 
s/he got motivated as online learning was sufficient in terms of "safety" said "There is a high level of safety. I feel confident and relaxed as it is only the course teacher who can see what I have done" (preservice teacher-number 6). Lastly,

Another preservice teacher who stated that $s /$ he got motivated as online learning provided an "alternative to social pressure" said "While studying my lessons or sitting for an exam, nobody watches you, and you can ask questions..." (preservice teacher-number 45).

\section{Theme of Satisfaction}

The theme of satisfaction included two sub-themes. One of the preservice teachers who stated that "instant feedback" provided by online learning increased his or her motivation regarding the dimension of satisfaction said "Regardless of time and place, we can communicate with others if we have access to the Internet, and this is quite a fast way of communication" (preservice teacher-number 37). Another preservice teacher who stated that $s /$ he got motivated as online learning allowed "saving time" said "It allows faster communication independently of time; you can easily find whatever you want; and you can store all your homework. These are all time-saving factors..." (preservice teachernumber 58).

When the sub-themes regarding the research data were examined, it was seen that different themes included the same sub-themes. In other words, the students stated that similar situations motivated them in different aspects within the scope of the ARCS model (Figure: 2).

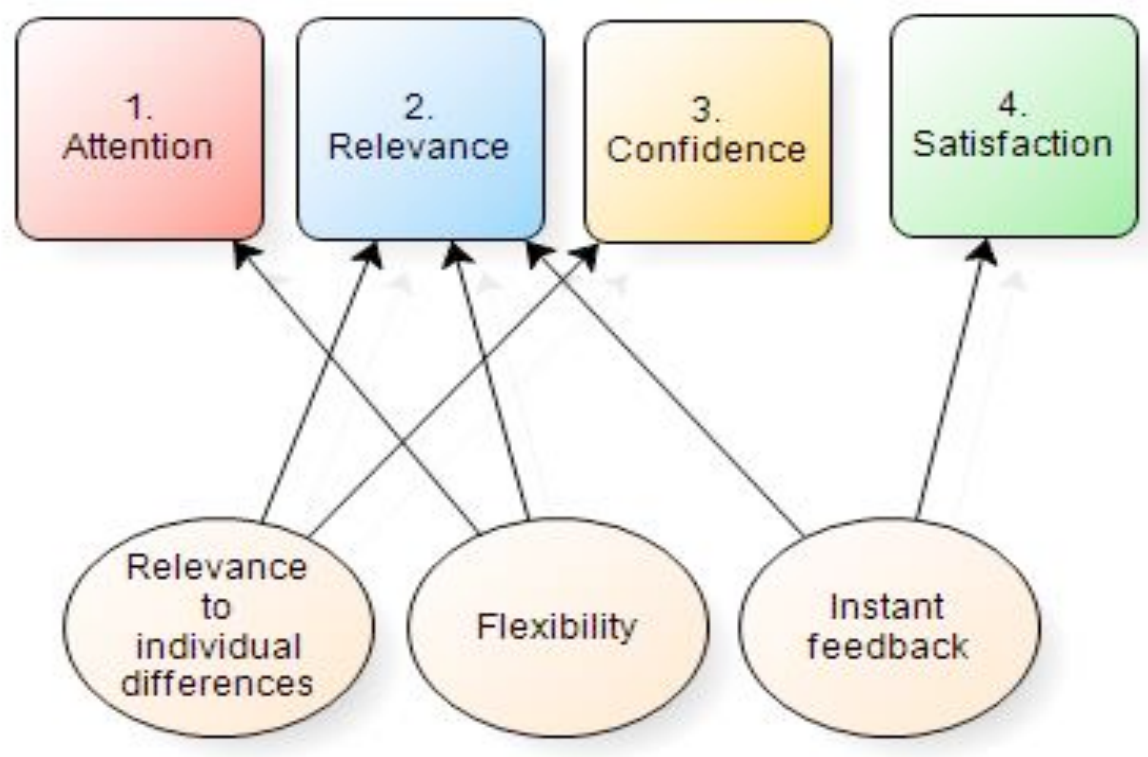

Figure: 2

Common Sub-Themes

As can be seen in Figure 2, the flexible structure of the online learning environment motivated the students in terms of the two sub-dimensions of attention and relevance. The relevance of the online learning environment to individual differences motivated the students with respect to the dimensions of relevance and confidence. Instant feedback provided for the students in the online learning environment motivated them in terms of the dimensions of relevance and satisfaction. 


\section{DISCUSSION AND CONCLUSION}

In the study, the factors motivating the online learners within the context of the ARCS model were determined. Regarding the dimension of "attention" of the ARCS model, it was found out that the students' motivation increased due to flexibility, multiple channel, source variety and interaction. In the study, it was also revealed that the presentation of content in the online environment in a way to address multiple channels drew the students' attention. Similarly, Mayer (2009) reported that the presentation of content for two channels (eye and ear) helped students learn better when compared to its presentation for a single channel. In addition, it is obvious that contents addressing more than one sense organ make learning more permanent. The finding obtained in the study that source variety increased the students' motivation is consistent with the finding of another study (Bonk, 2002) that variety in delivery format was a factor increasing motivation. In addition, it was found out in the study that interaction in online environment increased the students' motivation. This finding is also supported by Bonk (2002) who reported interaction to be an important factor that increased motivation at a moderate level. Similarly, Mclaren (2010) found out that interaction in online learning increased learners' level of satisfaction.

Regarding the dimension of "confidence" of the ARCS model, lack of social pressure, it was found out that the students' motivation increased confidence, progress under expert control and relevance to individual differences. In the study, the fact that learners can ask an expert for help in an online environment whenever they want and that they can progress under the control of that expert was found to make the participants feel themselves relaxed. This finding obtained in the study is parallel to that of another study carried out by Mclaren (2010) who reported that an instructor's availability had positive influence on online learners' satisfaction. Moreover, consistent with the finding of the present study that the online environment was safe, Bonk (2002) pointed out that learners' levels of motivation increase when an online learning environment has a "safe climate". Some of the participants reported that they were timid when compared to others in terms of their personal characteristics; that this situation could be considered within the scope of individual differences; and that they felt themselves in more comfort in the online learning environment as they did not see the other participants. In this respect, the sub-theme of relevance to individual differences and the sub-theme of lack of social pressure could be said to be two complementary sub-themes.

In the study, it was found out that regarding the dimension of "satisfaction" of the ARCS model, instant feedback and saving time increased the students' motivation. As for the dimension of "relevance", an important motivator in online learning environments (Hodges, 2004), relevance to individual differences, instant feedback and flexibility were found to increase motivation.

When the research findings obtained were examined, it was seen that some of the subthemes occurred in more than one dimension. Flexibility, relevance to individual differences and instant feedback were determined as the common sub-themes. All these common sub-themes were attached to the theme of relevance. In other words, it can be said that other themes ("attention", "confidence" and "satisfaction") supported "relevance" theme. In this context, if motivation in the dimensions of "attention", "confidence" and "satisfaction" provided, motivation in the dimension of "relevance" can be also provided. To understand this relationship, more researches are needed.

Parallel to the finding obtained in the present study that flexibility was one of the factors motivating the students for online learning, Sun, Tsai, Finger, Chen and Yeh (2008) reported that e-learning course flexibility was among the most important factors 
influential on learner satisfaction in e-learning. Similarly, in another study, Bonk (2002) found out that according to those giving online education, flexibility provided in an online learning environment had a moderate level of importance. When an online learning environment is designed in relevance to individual differences, learners' levels of motivation increase as they can study according to their own learning style (Keller \& Suzuki, 2004).

Similar to the sub-theme of relevance to individual differences found in the present study, Law, Lee and Yu (2010) reported that individual attitudes and expectations were among important motivators. Consistent with the finding obtained in the study that instant feedback in online learning increased the participants' levels of motivation, Hodges (2004) found out that feedback and navigation systems were among the factors motivating for online learning. Bonk (2002) and Mclaren (2010) reported that instant feedback provided in an online learning environment was quite important for motivation.

The results of the study demonstrated that the dimension of "confidence" was the one with the highest frequency $(f=55)$ influential on motivation in the online learning environment and that "satisfaction" was the one with the lowest frequency $(f=12)$. Besides this, the sub-theme of "relevance to individual differences" found under the category of "confidence" was the one most frequently mentioned by the participants $(f=31)$. In addition, "flexibility" found under the theme of "relevance" was the sub-theme with the lowest frequency $(f=3)$.

Depending on the results obtained in the present study, it could be stated that students' performance will increase if motivators for online learning determined regarding the dimensions of attention, relevance, confidence and satisfaction are taken into consideration while designing online learning environments.

The results of the present study are also thought to provide important implications for trainers, instructional designers and administrators dealing with online education and with its design. However, the present study has certain limitations. This study was carried out with the students attending the Department of Computer Education and Instructional Technologies at the Education Faculty of a state university.

A similar study could be designed involving students from other departments. In addition, another similar study could be conducted in other public or private institutions giving online education. The present study was carried out with online learners from a certain age group. Future studies on online learner motivation could be carried out with participants from different age groups.

\section{BIODATA and CONTACT ADDRESSSES of the AUTHORS}

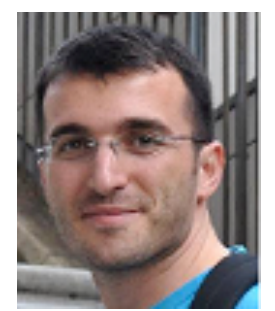

Dr. IZMIRLI is an assistant professor in the department of Computer Education \& Instructional Technology at Canakkale Onsekiz Mart University in Turkey. He received his PhD in the same department at Anadolu University. He is interested in multimedia learning, distance education, online learning, and instructional design.

Assist. Prof. Dr. Serkan IZMIRLI

Canakkale Onsekiz Mart University-COMU, Education Faculty

Department of Computer Education and Instructional Technology

Canakkale, TURKEY 
Tel: +902862171303

Fax: +902862120751

Email: sizmirli@gmail.com

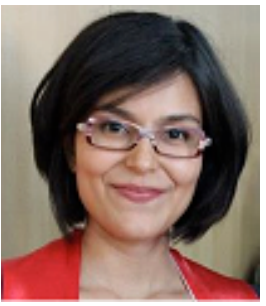

Dr. O. SAHIN IZMIRLI received her PhD in the department of Computer Education \& Instructional Technology at Anadolu University. Now she is an assistant professor in the same department at Canakkale Onsekiz Mart University. She is interested in ICT integration, instructional design, multimedia learning, and distance education.

Assist. Prof. Dr. Ozden SAHIN IZMIRLI

Canakkale Onsekiz Mart University-COMU, Education Faculty

Department of Computer Education and Instructional Technology

Canakkale, TURKEY

Tel: +902862171303

Fax: + 902862120751

Email: osahinizmirli@gmail.com

\section{REFERENCES}

Bonk, C. J. (2002). Online training in an online world. CourseShare.com. Retrieved on March 24, 2013 from http://publicationshare.com/docs/corp_survey.pdf

Brophy, J. (2010). Motivating students to learn (3rd edition). New York, NY: Routledge.

Chen, K.-C., \& Jang, S.-J. (2010). Motivation in online learning: Testing a model of selfdetermination theory. Computers in Human Behavior, 26(4), 741-752.

Chyung, S. Y. (2001). Systematic and systemic approaches to reducing attrition rates in online higher education. American Journal of Distance Education, 15(3), 36-49.

Clark, R. E. (2001). Media are "mere vehicles": The opening argument. In R.E. Clark (Ed.), Learning from media: Arguments, analysis, and evidence (2nd edition) (pp. 1-12). Greenwich, CT: Information Age.

Gabrielle, D. M. (2003). The effects of technology-mediated instructional strategies on motivation, performance, and self-directed learning. Unpublished Doctoral Dissertation, The Florida State University, Florida.

Hodges, C. B. (2004). Designing to motivate: Motivational techniques to incorporate in elearning experiences. The Journal of Interactive Online Learning, 2(3), 1-7.

Keller, J. M. (1987a). Development and use of the ARCS model of instructional design. Journal of Instructional Development, 10 (3), 2-10.

Keller, J. M. (1987b). Strategies for stimulating the motivation to learn. Performance \& Instruction, 26(8), 1-7.

Keller, J. M. (1997). Motivational design and multimedia: Beyond the novelty effect. Strategic Human Resource Development Review, 1(1), 188-203.

Keller, J. M. (1999). Motivation in cyber learning environments. International Journal of Educational Technology, 1(1), 7-30. 
Keller, J. M., \& Suzuki, K. (2004). Learning motivation and e-learning design: A multinationally validated process. Journal of Educational Media, 29(3), 229-239.

Law, K. M., Lee, V., \& Yu, Y.T. (2010). Learning motivation in e-learning facilitated computer programming courses. Computers \& Education, 55(1), 218-228.

Levy, Y. (2007). Comparing dropouts and persistence in e-learning courses. Computers \& Education, 48, 185-204.

Mayer, R. E. (2009). Multimedia learning ( ${ }^{\text {nd }}$ Eds). New York, USA: Cambridge University Press.

Mcgreal, R., \& Elliott, M. (2008). Technologies of Online Learning (E-learning) In Terry Anderson (Ed.), The Theory and Practice of Online Learning (2nd ed.) (pp. 143-165). Edmonton: AU Press, Athabasca University.

Mclaren, A. C. (2010). The Effects of Instructor-Learner Interactions on Learner Satisfaction in Online Masters Courses. Wayne State University Dissertations. Retrieved on February 20, 2013 from http://digitalcommons.wayne.edu/oa_dissertations/105

Mertens, D. M. (2009). Research and evaluation in education and Psychology integrating diversity with Quantitative, Qualitative, and Mixed methods (3th ed.). California: Sage Publications.

Miltiadou, M., \& Savenye, W.C. (2003). Applying social cognitive constructs of motivation to enhance student success in online distance education. AACE Journal, 11 (1), 78-95.

Miles, B. M., \& Huberman, A. M. (1994). Qualitative data analysis (2nd ed.). London: Sage Publications.

Patton, M. Q. (1990). Qualitative Evaluation and Research Methods (2nd ed.). Newbury Park, CA: Sage Pub.

Patton, M. Q. (2002). Qualitative research and evaluation methods. Thousand Oaks, CA: Sage.

Sawang, S., Newton, C., \& Jamieson, K. (2013). Increasing learners' satisfaction/intention to adopt more e-learning. Education + Training, 55(1).

Shank, P., \& Sitze, A. (2004). Making sense of online learning: A guide for beginners and the truly skeptical. San Francisco: Pfeiffer.

Smith, R. (2008) Motivational Factors in E-Learning. Retrieved on June 15, 2013 from, http://www.ruthcsmith.com/GWU\%20Papers/Motivation.pdf

Song, S. H., \& Keller, J. M. (2001). Effectiveness of motivationally adaptive computerassisted instruction on the dynamic aspects of motivation. Educational Technology Research and Development, 49(2), 5-22.

Sun, P. C., Tsai, R. J., Finger, G., Chen, Y.-Y., \& Yeh, D. (2008). What drives a successful elearning? An empirical investigation of the critical factors influencing learner satisfaction. Computers \& Education, 50(4), 1183-1202.

Wlodkowski, R. J. (1985). Enhancing adult motivation to learn: A comprehensive guide for teaching all adults (3rd edition). San Francisco: Jossey-Bass. 
Yıldırım, A., \& Simsek, H. (2008). Sosyal bilimlerde nitel araştırma yöntemleri [Qualitative Research Methods in Social Sciences]. Ankara: Seçkin Yayıncılık.

Yukselturk, E., \& Bulut, S. (2007). Predictors for student success in an online course. Educational Technology \& Society, 10(2), 71-83. 